Bulletin of the Seismological Society of America. Vol. 55, No. 6, pp. 971-974. December, 1965

\title{
A NOTE ON THE EXISTENCE OF RELATIVE MAXIMA AND MINIMA ON PHASE VELOCITY CURVES
}

\author{
By E. N. Thrower and D. G. Harkrider
}

ABSTRACT

\begin{abstract}
Phase and group velocity dispersion curves for fundamental Rayleigh waves have been computed with more precision than previously attempted. The new curves show a relative minimum in phase velocity at periods near 50 sec for four perturbed Gutenberg continental models.
\end{abstract}

It is often assumed that the phase velocity curves for Rayleigh waves on a layered half-space are monotonically increasing functions of increasing period. A few years ago Harkrider, Hales, and Press (1963) published a study on the feasibility of detecting a low velocity layer in the mantle using Rayleigh wave phase velocities. The theoretical Rayleigh wave velocities presented in that paper were calculated with a program which used this assumed monotomic property to determine the mode order (Press, Harkrider, and Seafeldt, 1961). For some of their velocity models there was a computationaly anomalous period region in which the programs failed to find a period, $T$, for the fundamental mode. The program using phase velocity, $c$, as the input parameter was unable to obtain a period in this region with a decrease in $c$ of $0.0001 \mathrm{~km} / \mathrm{sec}$ at the long period boundary or an equal increase in $c$ at the short period boundary. These models were characterized by a deep layer with a velocity much smaller than the velocities of the layers above it.

In an attempt to find periods in the anomalous region, we reran their cases with modified programs in which the period was the input and in which there were no assumptions as to the form of the $(c, T)$ curve (Thrower, 1965). We found that the difficulty was not due to a broad, extremely flat plateau as previously concluded. It was actually due to the presence of a relative minimum at the long period limit of the anomalous region with a relative maximum between this minimum and the short period normal segment of the phase velocity curve. These results are shown in Figures 1, 2, 3, and 4 for some perturbed Gutenberg continental models as defined in Harkrider, Hales, and Press (1963).

Even with the large density of new dispersion values and their associated displacements with depth showing typical fundamental mode characteristics there was some question at first as to whether the roots represented the same mode with inverse dispersion, or a collection of values from closely spaced higher modes with normal dispersion. In order to verify that this was indeed a region of increasing phase velocity with decreasing period, it was necessary to determine the slope at the root without having to justify that the neighboring roots belonged to the same mode. This was accomplished by calculating "analytic" group velocities.

The group velocity, $U$, shown on the figures as a solid line is defined as

$$
U \equiv \frac{d \omega}{d k}=-\left(\frac{\partial F}{\partial k}\right)_{\omega} /\left(\frac{\partial F}{\partial \omega}\right)_{k}
$$


where

$$
\begin{aligned}
& \omega=2 \pi / T, \quad \text { angular frequency } \\
& k=\omega / c, \quad \text { angular wave number }
\end{aligned}
$$

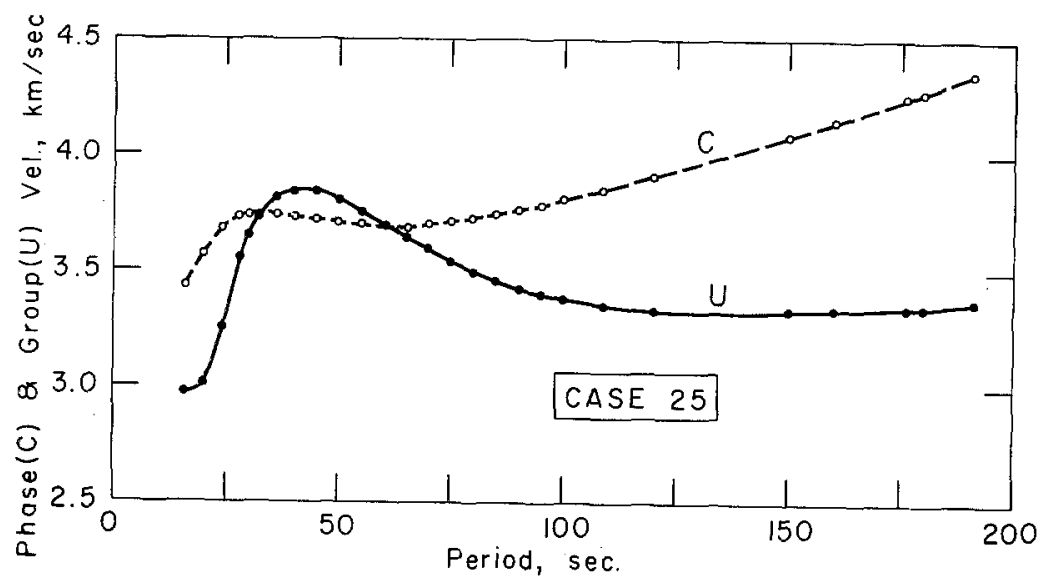

FIG. 1. Phase and group velocity dispersion curves of the fundamental mode for a perturbed Gutenberg continental model. Case 25 has a $10 \mathrm{~km}$ thick low velocity layer of $2.0 \mathrm{~km} / \mathrm{sec}$ shear velocity inserted at a midpoint depth of $105 \mathrm{~km}$.

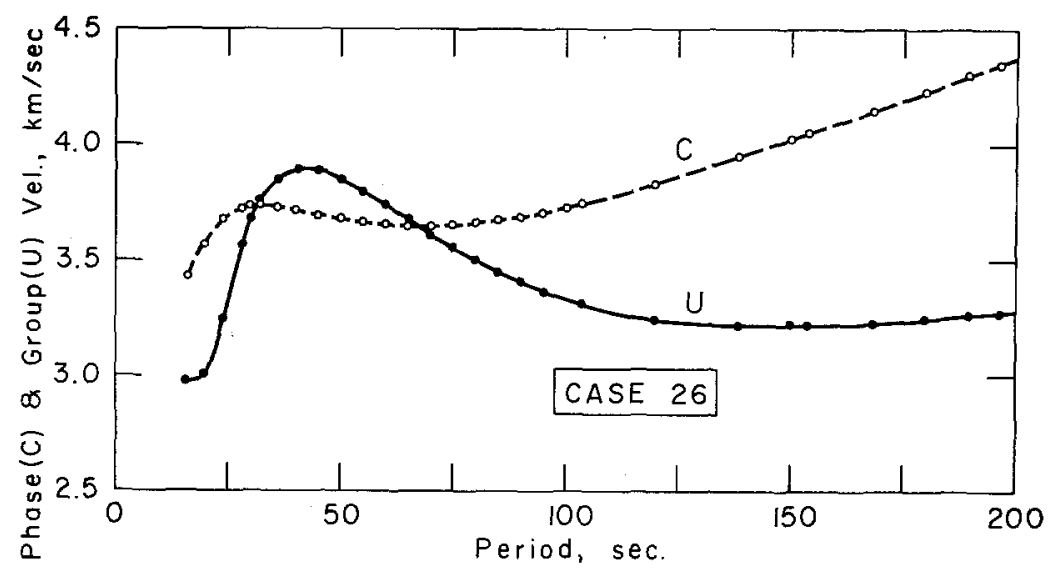

Fig. 2. Phase and group velocity dispersion curves of the fundamental mode for a perturbed Gutenberg continental model. Case 26 has a $1 \mathrm{~km}$ thick low veloeity layer of $0.5 \mathrm{~km} / \mathrm{sec}$ shear velocity inserted at a midpoint depth of 100.5 .

and $F=0$ is the period equation defining the dispersion curves. The partial derivatives appearing in equation (1) were computed at each of the roots without recourse to numerical differentiation by methods described in detail by Harkrider (1964). Briefly, differentiation of the continued matrix product defining the func- 
tion $F$ yields expressions for the partial derivatives which can themselves be evaluated by a similar sequence of matrix multiplications. Using this calculated group velocity and the relation.

$$
\frac{1}{U}=\frac{1}{c}+\frac{T}{c^{2}} \frac{d c}{d T}
$$

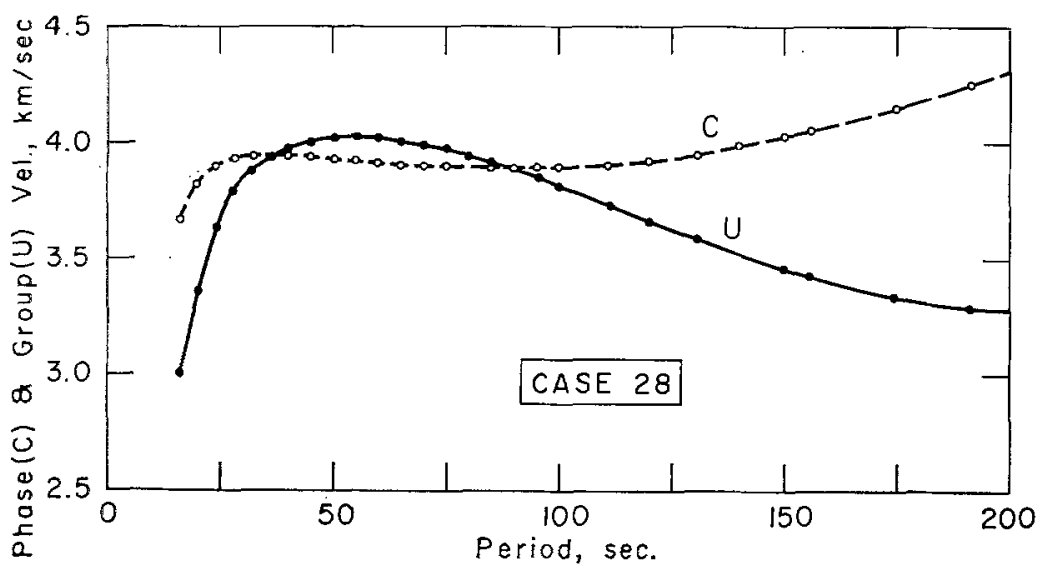

FIG. 3. Phase and group velocity dispersion curves of the fundamental mode for a perturbed Gutenberg continental model. Case 28 has a $10 \mathrm{~km}$ thick low velocity layer of $2.0 \mathrm{~km} / \mathrm{sec}$ shear velocity inserted at a midpoint depth of $205 \mathrm{~km}$.

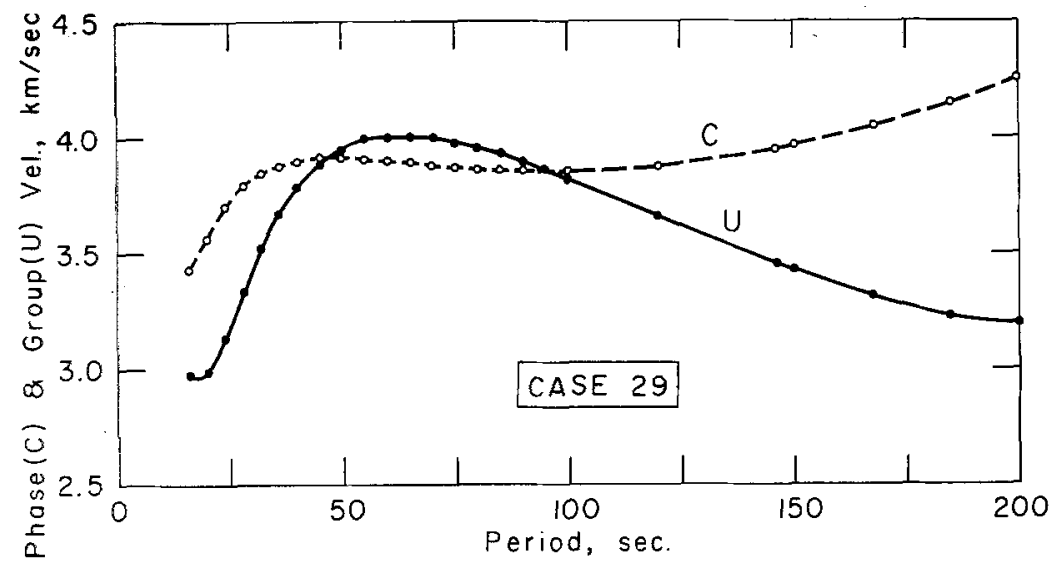

FIG. 4. Phase and group velocity dispersion curves of the fundamental mode for a perturbed Gutenberg continental model. Case 29 has a $1 \mathrm{~km}$ thick low velocity layer of $0.5 \mathrm{~km} / \mathrm{sec}$ shear velocity inserted at a midpoint depth of $200.5 \mathrm{~km}$.

the value of $d c / d T$ at each period can be determined without reference to other roots, and using the normal output of the program.

From the figures, we see that the group velocity is greater than the phase velocity for a portion of the anomalous region and from equation (2), we have $d c / d T<0$. Therefore, with the calculation of just one root in this region, one can show that 
phase velocity does not monotonically increase with increasing period for this structure. Also note that the group and phase velocity curves intersect at the relative maxima and minima of the phase velocity curve as predicted by equation (2).

\section{ACKNOWLEDGMENT}

This research was supported by the Advanced Research Projects Agency and was monitored by the Air Force Office of Scientific Research under Contract AF-49(638)-1337.

This research also formed part of the program of the Road Research Board of the Ministry of Transport (Gt. Britain).

\section{REFERENCES}

Harkrider, D. B., A. L. Hales, and F. Press (1963). On detecting soft layers in the mantle with Rayleigh waves, Bull. Seism. Soc. Am. 53, 539-548.

Harkrider, David G. (1964). Theoretical and observed acoustic-gravity waves from explosive sources in the atmosphere, J. Geophys. Res. 69, 5295-5321.

Press, Frank, D. Harkrider, and C. A. Seafeldt (1961). A fast convenient program for computation of surface wave dispersion curves in multilayered media, Bull. Seism. Soc. Am. 51, 495-502.

Thrower, E. N. (1965). The computation of dispersion eurves on layered media, J. Sound Vib. $2,3,14-30$.

E. N. THROWER

Spectal Problems Section

Materials and Construction Division

Road Research Laboratory

Harmondsworth, West Drayton

Mtdolesex, England

D. G. HARKRIDER

Seismological Laboratory

California Institute of Technology

Pasadena, California

(Division of the Geological Sciences, Contribution No. 1322)

Manuscript received March 1, 1965. 